\title{
Применение лечебного пиобактериофага секстафага в комплексном лечении больных с деструктивным холециститом
}

\author{
Р. Р. Бабаева \\ Азербайджанский медицинский университет, г. Баку

\section{Application of remedial pyobacteriophag sextaphag in complex of treatment in destructive cholecystitis}

\author{
R. R. Babaeva \\ Azerbaijani Medical University, Baku
}

\section{Реферат}

Цель. Оценить эффективность применения лечебного пиобактериофага секстафага для снижения частоты послеоперационных инфекционных осложнений после лапароскопической холецистэктомии (ЛХЭ) при деструктивных формах острого калькулезного холецистита (ОКХ).

Материалы и методы. Изучены показатели бактериохолии, микробной обсемененности отделяемого по дренажной трубке из подпеченочного пространства после ЛХЭ, эндогенной интоксикации, функционального состояния печени, цитокинового статуса, а также воспалительной реакции у 76 больных с разными формами ОКХ с оценкой эффективности локального применения лечебного поливалентного пиобактериофага секстафага и антисептика декасана.

Результаты. Местное использование лечебного поливалентного пиобактериофага секстафага и антисептика декасана после ЛХЭ у больных с деструктивными формами ОКХ за короткие сроки подавляло рост микрофлоры, ускоряло регрессию воспалительной реакции, что привело к снижению частоты послеоперационных гнойно-воспалительных осложнений с 18,9 до 5,4\%.

Выводы. Местное применение лечебного поливалентного пиобактериофага секстафага с декасаном после ЛХЭ улучшает результаты лечения больных с деструктивными формами ОКХ.

ключевые слова: острый калькулезный холецистит; лапароскопическая холецистэктомия; лечебные бактериофаги.

Abstract

Objective. To estimate the efficacy of application of remedial pyobacteriophag sextaphag for lowering of the postoperative infectious morbidity rate after laparoscopic cholecystectomy (LCHE) in destructive forms of an acute calculous cholecystitis $(\mathrm{ACCH})$

Materials and methods. The indices of bacteriocholia, microbial dissemination of excretion via a drainage tube, installed in subhepatic space after LCHE, endogenous intoxication, functional state of the liver, the cytokin's status were studied up, as well as inflammatory reaction in 76 patients, suffering various forms of an ACCH with estimation of efficacy of local application of remedial polyvalent pyobacteriophag sextaphag with antiseptic preparation decasan.

Results. Local application of remedial polyvalent pyobacteriophag sextaphag with decasan after LCHE in patients, suffering destructive forms of an $\mathrm{ACCH}$, in a short period of time have been resulted in suppression of the microflora raise, acceleration of the inflammatory reaction regression, what was followed by lowering of the postoperative purulent-inflammatory morbidity rate from 18.9 to $5.4 \%$.

Conclusion. Local application of remedial polyvalent pyobacteriophag sextaphag with decasan after LCHE improves the results of treatment in patients, suffering destructive forms of an ACCH.

Key words: acute calculous cholecystitis; laparoscopic cholecystectomy; remedial bacteriophags.

Лапароскопическую холецистэктомию (ЛХЭ) считают «золотым стандартом» в лечении желчнокаменной болезни и ее осложнений [1 - 7]. Несмотря на внедрение миниинвазивных технологий, применение современных антибактериальных препаратов, частота послеоперационных гнойно-воспалительных осложнений остается высокой и не имеет тенденции к снижению [8].

Недостаточная эффективность антибиотикопрофилактики и антибактериальной терапии в связи с антибиотикорезистентностью штаммов микробов, низкая их биодоступность в очаг инфекции и изменение фармакокинетики применяемых антибактериальных препаратов побудили хирургов в последние годы применять лечебные бактери- офаги [9, 10], которые оказывают специфическое лизирующее действие в отношении многих бактерий, не имеют противопоказаний к применению, не оказывают побочного действия и не сопровождаются осложнениями [9].

Цель исследования: оценить эффективность применения лечебного пиобактериофага секстафага для снижения частоты послеоперационных инфекционных осложнений после ЛХЭ при деструктивных формах острого холецистита.

\section{Материалы и методы исследования}

Проанализированы результаты лечения 75 больных в возрасте от 18 до 80 лет с ОКХ. Мужчин было 32 (42,7\%), 
женщин - 43 (57,3\%). Всем больным проведено комплексное обследование - рентгеноскопия грудной и брюшной полостей, ультразвуковое исследование, фиброгастродуоденоскопия, по показаниям - компьютерная и магнитно-резонансная томография, эндоскопическая ретроградная холангиопанкреатография.

Диагноз острого холецистита устанавливали с учетом диагностических критериев Токийских клинических рекомендаций (TG13). Степень тяжести состояния пациентов определяли тоже на основе данных рекомендаций [11]. У 18 больных ОКХ осложнился перивезикальным инфильтратом (9), перивезикальным абсцессом (6) и местным перитонитом (3).

В зависимости от способа лечения больных распределили на две группы. В 1-ю группу (контрольную) включили 37 больных: 12 - с катаральной формой ОКХ, 14 с флегмонозной, 11 - с гангренозной; І степень тяжести состояния отмечена у 26, II - у 11 больных. Этим больным на фоне общепринятой базисной терапии в конце ЛХЭ проводили местную санацию физиологическим раствором и 0,02\% раствором фурацилина. В раннем послеоперационном периоде на фоне антибиотикотерапии для санации местного очага вводили через дренажную трубку, оставленную в подпеченочном пространстве, 20 - 30 мл фурацилина и 10 мл 1\% раствора диоксидина. Во 2-ю группу (основную) вошли 38 больных: 13 - с катаральной формой ОКХ, 13 - с флегмонозной, 12 - с гангренозной; I степень тяжести состояния отмечена у 24 ,
II - у 13, III - у 1 больного. Этим больным после местной санации физиологическим раствором и 50 - 100 мл раствора сильного антисептика декасана проводили орошение раствором поливалентного лечебного бактериофага в количестве 20 - 30 мл. Спустя 8 ч после операции через дренажную трубку сначала вводили 30 - 40 мл декасана, спустя 10 - 15 мин после его аспирации - 20 - 30 мл бактериофага и пережимали трубки на 20 - 30 мин. При катаральной форме ОКХ после ЛХЭ декасан и бактериофаг вводили только один раз и антибиотикотерапию не проводили. При флегмонозной форме ОКХ после ЛХЭ декасан и бактериофаг вводили через каждые 8 ч в тех же объемах всего 3 раза. При гангренозной форме ОКХ в конце оперативного вмешательства очаг воспаления после санации декасаном орошали раствором бактериофага в объеме 100 - 150 мл. В послеоперационном периоде через дренажную трубку каждые 8 ч в течение 2 сут после санации декасаном водили 20 - 30 мл бактериофага. При флегмонозной форме ОКХ антибиотик применяли в течение первых суток, при гангренозной - двое суток.

В качестве лечебного бактериофага использовали поливалентный пиобактериофаг секстафаг, который специфически лизирует стафилококки, стрептококки, эшерихии коли, протеи, псевдомонас аэругиноза и клебсиеллы. Для санации очага воспаления использовали декасан - новый антисептический препарат, который имеет выраженное бактерицидное, фунгицидное, антипротозойное и вирусоидное действие [12].

\begin{tabular}{|c|c|c|c|c|c|}
\hline \multicolumn{6}{|c|}{$\begin{array}{l}\text { Сравнительная динамика изменений некоторых биохимических и иммунологических показателей } \\
\text { воспалительной реакции у больных контрольной и основной групп }\end{array}$} \\
\hline \multirow{3}{*}{ Показатель } & \multirow{3}{*}{ Группа } & \multicolumn{3}{|c|}{ Сроки исследования (сут) } & \multirow{3}{*}{ Норма } \\
\hline & & \multirow{2}{*}{ до операции } & \multicolumn{2}{|c|}{ после операции } & \\
\hline & & & $3-и$ & 5 -e & \\
\hline \multirow{2}{*}{ Общий белок, г/л } & K & $5,49 \pm 0,11 * * *$ & $5,17 \pm 0,10 * * * \wedge$ & $5,70 \pm 0,12 * * *$ & \multirow{2}{*}{$7,07 \pm 0,15$} \\
\hline & 0 & $5,44 \pm 0,10 * * *$ & $5,27 \pm 0,10 * * *$ & $6,13 \pm 0,10 * * * \wedge \wedge \wedge \S$ & \\
\hline \multirow{2}{*}{ Альбумин, г/л } & K & $3,32 \pm 0,10 * * *$ & $3,02 \pm 0,09 * * * \wedge$ & $3,43 \pm 0,10 * * *$ & \multirow{2}{*}{$4,09 \pm 0,14$} \\
\hline & 0 & $3,26 \pm 0,10 * * *$ & $3,09 \pm 0,10 * * *$ & $3,74 \pm 0,12^{\wedge \wedge}$ & \\
\hline \multirow{2}{*}{ СРП, мг/л } & $\mathrm{K}$ & $11,5 \pm 0,9 * * *$ & $15,6 \pm 1,1 * * * \wedge \wedge$ & $7,8 \pm 0,5 * * * \wedge \wedge$ & \multirow{2}{*}{$3,5 \pm 0,4$} \\
\hline & 0 & $11,5 \pm 0,9 * * *$ & $13,3 \pm 1,0 * * *$ & $5,9 \pm 0,4 * * * \wedge \wedge \wedge \S \S$ & \\
\hline \multirow{2}{*}{ Ферритин, нг/мл } & $\mathrm{K}$ & $405,6 \pm 21,6 * * *$ & $319,5 \pm 20,6 * * * \wedge \wedge$ & $228,8 \pm 15,4 * * * \wedge \wedge \wedge$ & \multirow{2}{*}{$136,1 \pm 8,1$} \\
\hline & 0 & $397,8 \pm 22,4 * * *$ & $278,1 \pm 16,1 * * * \wedge \wedge \wedge$ & $166,2 \pm 9,2^{\wedge \wedge \wedge} \S \S \S$ & \\
\hline \multirow{2}{*}{$\mathrm{ACT}, \mathrm{U} / \mathrm{I}$} & K & $52,2 \pm 5,1 * * *$ & $62,6 \pm 5,6 * * *$ & $33,3 \pm 3,7 * * \wedge \wedge$ & \multirow{2}{*}{$19,1 \pm 2,1$} \\
\hline & 0 & $48,7 \pm 4,5^{* * *}$ & $55,3 \pm 5,2 * * *$ & $23,5 \pm 2,2^{\wedge \wedge \wedge} \S \S$ & \\
\hline \multirow{2}{*}{ АлТ, U/I } & $\mathrm{K}$ & $54,7 \pm 5,5^{* * *}$ & $68,1 \pm 6,5^{* * *}$ & $34,1 \pm 3,5^{* * * \wedge \wedge}$ & \multirow{2}{*}{$18,4 \pm 1,9$} \\
\hline & 0 & $56,5 \pm 5,6 * * *$ & $62,6 \pm 6,2^{* * *}$ & $26,3 \pm 2,5^{\wedge \wedge \wedge} \S$ & \\
\hline \multirow{2}{*}{ ИЛ-1, пг/мл } & $\mathrm{K}$ & $16,4 \pm 1,7^{* * *}$ & $24,9 \pm 2,2 * * * \wedge \wedge \wedge$ & $14,6 \pm 1,7^{* * *}$ & \multirow{2}{*}{$5,1 \pm 0,7$} \\
\hline & 0 & $15,8 \pm 1,5^{* * *}$ & $20,9 \pm 1,5 * * * \wedge \wedge$ & $9,9 \pm 0,7 * * * \wedge \wedge \S$ & \\
\hline \multirow{2}{*}{ ИЛ-2, пг/мл } & $\mathrm{K}$ & $4,04 \pm 0,32 *$ & $4,42 \pm 0,34^{*}$ & $4,84 \pm 0,36^{*}$ & \multirow{2}{*}{$6,04 \pm 0,71$} \\
\hline & 0 & $3,96 \pm 0,28 *$ & $4,74 \pm 0,35$ & $5,42 \pm 0,45^{\wedge}$ & \\
\hline \multirow{2}{*}{ ИЛ-4, пг/мл } & $\mathrm{K}$ & $15,27 \pm 1,6 * * *$ & $29,94 \pm 3,14 * * * \wedge \wedge \wedge$ & $9,10 \pm 1,27 * * * \wedge \wedge \wedge$ & \multirow{2}{*}{$2,45 \pm 0,32$} \\
\hline & 0 & $15,70 \pm 1,71 * * *$ & $23,24 \pm 2,1 * * * \wedge \wedge$ & $5,38 \pm 0,62 * * * \wedge \wedge \wedge \S \S$ & \\
\hline \multirow{2}{*}{ СМП, г/л } & K & $0,84 \pm 0,04 * * *$ & $1,03 \pm 0,06 * * * \wedge$ & $0,73 \pm 0,04^{* * * \wedge}$ & \multirow{2}{*}{$0,50 \pm 0,03$} \\
\hline & 0 & $0,85 \pm 0,04 * * *$ & $0,92 \pm 0,05^{* * *}$ & $0,64 \pm 0,03 * * \wedge \wedge \wedge$ & \\
\hline \multicolumn{6}{|c|}{ 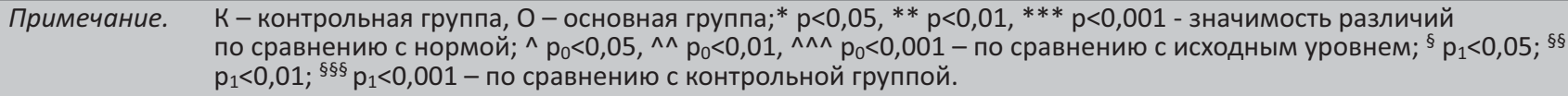 } \\
\hline
\end{tabular}




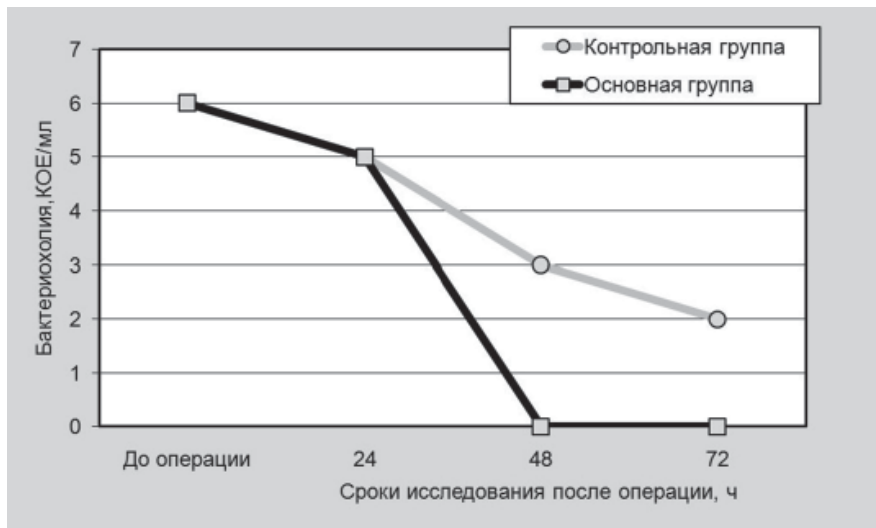

Puc. 1.

Сравнительная динамика уровня микробной контаминации отделяемого по дренажной трубке в изучаемых группах больных.

В интраоперационно взятой желчи определяли состав микрофлоры и степень микробной контаминации. Также в динамике проводили микробиологическое исследование промывной жидкости - отделяемого по дренажной трубке из подпеченочного пространства.

С целью сравнительного изучения влияния лечебного бактериофага на течение воспалительной реакции до операции, на 3-и и 5-е сут после операции в крови определяли содержание общего белка, альбумина, среднемолекулярных пептидов (СМП), С-реактивного протеина (СРП), общего билирубина, ферритина, аланинаминотрансферазы (АЛТ), аспартатаминотрансферазы (АСТ), щелочной фосфотазы (ЩФ), гамма-глутаминтрансферазы (ГГТ), интерлейкинов 1, 2, 4 (ИЛ-1, ИЛ-2, ИЛ-4), гематокрита, остаточного азота, мочевины, креатинина, а также измеряли температуру тела, частоту пульса, изучали лейкоцитоз и скорость оседания лейкоцитов.

За норму изучаемых показателей приняли их значения у 15 практически здоровых людей.

Для статистической обработки полученных данных использовали методы вариационной и непараметрической статистики (критерий Вилкоксона-Манна-Уитни).

\section{Результаты}

Микробиологическим исследованием пузырной желчи у 41 (54,7\%) из 75 больных выявили бактериобилию: у 35 больных с деструктивными формами ОКХ, у 6 - с катаральным воспалением желчного пузыря. У 68,3\% больных обнаружена грамотрицательная, у 31,7\% - грамположительная микрофлора. В желчи у 73,2\% больных наблюдали монокультуру. В биликультурах преобладали Escherichia coli, Pseudomonas aeruginosa, Staphylococcus aureus и Klebsiella spp. Уровень бактериохолии был в пределах $10^{3}-10^{9}$ колониеобразующих единиц (КОЕ)/мл. Степень микробной контаминации зависела от формы ОКХ: при катаральной форме - $10^{3}-10^{4} \mathrm{KOE} / \mathrm{мл}$ флегмонозной $-10^{6}-10^{8} \mathrm{KOЕ/мл,} \mathrm{гангренозной}-10^{7}-10^{9}$ КОЕ/мл.

Изучение бактериальной обсемененности промывной жидкости - отделяемого по дренажной трубке из подпеченочного пространства показало, что у больных основ-

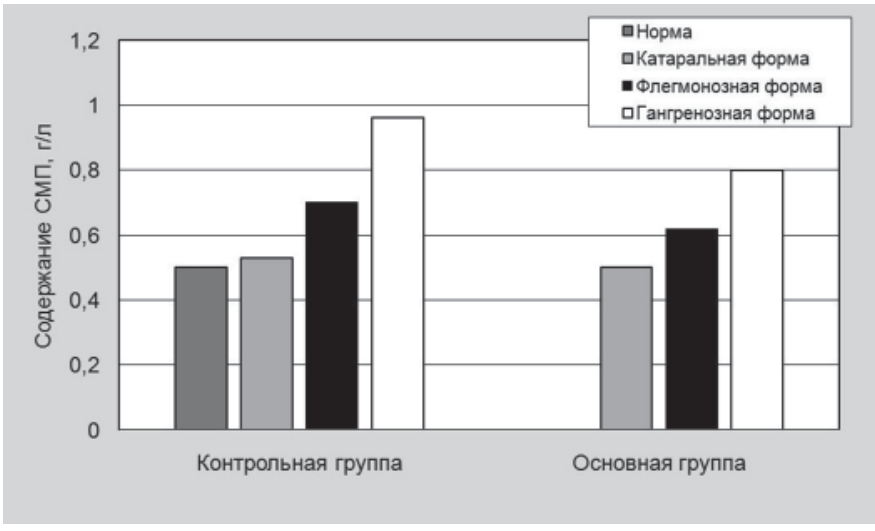

Puc. 2.

Сравнительная оценка содержания СМП на 5-е сут после ЛХЭу больных обеих групп в зависимости от клинической формы ОКХ.

ной группы на фоне применения лечебного бактериофага и декасана через 2 сут после ЛХЭ рост микробов отсутствовал (рис. 1).

На основании сравнительного изучения основных клинико-лабораторных, биохимических и иммунологических показателей у обеих группах сделан вывод о том, что локальное применение лечебного поливалентного бактериофага секстафага позитивно саногенно влияет на течение воспалительной реакции, приводя к ее завершению (см. маблиму).

Проведенными исследованиями также установлено, что включение в комплекс базисной терапии местного применения секстафага при всех формах ОКХ значительно ускорило регрессию воспалительного процесса и тем самым снизило уровень эндогенной интоксикации (рис. 2).

Позитивная динамика течения послеоперационного периода после ЛХЭ в основной группе сопровождалась более быстрым клиническим улучшением состояния пациентов. Никто из пациентов в обеих группах не умер.

\section{Обсуждение}

При деструктивных формах ОКХ частота выделения микроорганизмов в пузырной желчи выше, чем при катаральной форме воспаления.

На основании проведенных исследований в обеих группах выявлены общие закономерности в течении воспалительной реакции. В первые 3 сут после ЛХЭ происходит активация воспалительной реакции, в дальнейшем отмечены ее положительная динамика и завершение. Выявленная высокая клиническая әффективность применения антисептика декасана и поливалентного лечебного пиобактериофага секстафага в профилактике послеоперационных гнойно-воспалительных осложнений, выражавшаяся в снижении частоты их развития, ускоренной нормализации клинико-лабораторных и микробиологических показателей (температуры тела, уровней биомаркеров воспалительного процесса, цитокинов, функциональных показателей печени, снижении степени бактериальной обсемененности) и сокращении длительности течения воспалительного процесса, доказывает целесообразность включения указанных препаратов в комплекс- 
ную терапию при деструктивных формах ОКХ.

Сравнительный анализ полученных результатов показал, что местное применение лечебного поливалентного пиобактериофага секстафага с декасаном позволяет снизить частоту послеоперационных гнойно-воспалительных осложнений с 18,9 до 5,4\% и значительно улучшить результаты хирургического лечения.

\section{Выводы}

1. Уровень бактериохолии при ОКХ зависит от выраженности воспалительного процесса в желчном пузыре и осложнений.

2. При деструктивных формах ОКХ включение в лечебный комплекс местного применения лечебного поливалентного пиобактериофага секстафага с антисептиком декасаном быстрыми темпами снижает уровень микробной контаминации и ускоряет тенденцию к регрессии воспалительной реакции, предупреждает развитие послеоперационных гнойно-воспалительных осложнений и значительно улучшает результаты лечения.

\section{Подтверждения}

\section{Информация о финансировании}

Это исследование является фрагментом плановой НИР. Финансирование за счет госбюджета.

\section{Конфликт нтересов}

Автор декларирует отсутствие конфликта интересов.

\section{References}

1. Coccolini F, Catena F, Pisano M, Gheza F, Fagiuoli S, Di Saverio S, et al. Open versus laparoscopic cholecystectomy in acute cholecystitis. Systematic review and meta-analysis. Int J Surg. 2015 June;(18):196204. https://doi.org/10.1016/j.ijsu.2015.04.083.

2. Gurusamy KS, Davidson C, Gluud C, Davidson BR. Early versus delayed laparoscopic cholecystectomy for people with acute cholecystitis. Cochrane Database Syst Rev. 2013 Jun;(6):CD005440. https://doi. org/10.1002/14651858.cd005440.pub3.

3. Pisanu A, Reccia I, Porceddu G, Uccheddu A. Meta-analysis of prospective randomized studies comparing single - incision laparoscopic cholecystectomy (SILS) and conventional multiport laparoscopic cholecystectomy (CMLC). J Gastointest Surg. 2012 Sep;16(9):1790-801. https://doi.org/10.1007/s11605-012-1956-9.

4. Gurusamy K, Samraj K, Gluud C. Meta-analysis of randomized controlled trials on the safety and effectiveness of early versus delayed laparoscopic cholecystectomy for acute cholecystitis. Br J Surg. 2010 Feb;97(2):141-50. https://doi.org/10.1002/bjs.7076.

5. Navez B, Ungureanu F, Michiels M, Claeys D, Muysoms F, Hubert C, et al. Surgical management of acute cholecystitis: results of a 2 year prospective multicenter survey in Belgium. Surg Endosc. 2012 Sept;26(9):2436-45. https://doi.org/10.1007/s00464-012-2206-7.

6. Madhu C, Senthil Kumar R. Compare the effectiveness of early versus delayed laparoscopic cholecystectomy in acute calculus cholecystitis. Int Surg J. 2018 Feb;5(2):695-700. https://doi.org/10.18203/23492902.isj20180376.

7. Zafar S, Obirize A, Adesibikan B, Cornwell E, Fullum T, Tran D. Optimal time for early laparoscopic cholecystectomy for acute cholecystitis. JAMA. 2015 Feb;150(2):129-36. https://doi.org/10.1001/jamasurg.2014.2339.

8. Hjuseynəliyev AH. Kəskin daşılı holesistit zamanı orjaanizmin sitokin statusu vəziyyətinin jaiymətləndirilməsi və onun tənzimlənməsi. [tezisy]. Bak1; 2015. 22 s. [In Azerbaijan].

9. Bondarev RV, Bondarev VI, Selivanov SS, Orehov AA. Primenenie adaptirovannyh bakteriofagov $\mathrm{v}$ kompleksnom lechenii bol'nyh ostrym gnojnym holangitom. Ukrainskij Zhurnal Hirurgii. 2011;(5):150-4. [In Russian].

10. Ivancok VM, Bondarev RV, Sopko AI, Kozubovich RN, Mishalov VG. Ocenka rezultatov lecheniia ostrogo destruktivnogo holecistita posle laparoskopicheskoi holecistjektomii u bolnyh raznyh vozrastnyh grupp i puti ih uluchshenija u lic starshe 60 let s serdechnoi nedostatochnostiu ishemicheskogo geneza. Kharkivka khirurhichna Shkola. 2015;(2):49 -51 . [In Russian].

11. Takada T, Strasberg SM, Solomkin JS, Pitt H, Gomi H, Yoshida M, Mayumi T. Updated Tokyo Guidelines for the management of acute cholangitis and cholecystitis. J Hepatobiliary Pancreat Sci. 2013 Jan;20(1):17. https://doi.org/10.1007/s00534-012-0566-y.

12. Fomin PD, Lissov AI, Kozlov SN, Mihalchishhin SN. Primenenie antiseptika Deksan v neotlozhnoy abdominalnoy hirurgii. Klin khir 2009;(11-12):98-100. [In Russian]. 